\title{
High prevalence of primary dyslipidaemia in black South African patients at a tertiary hospital in northern Gauteng, South Africa
}

\author{
A A Khine, ${ }^{1}$ MD, MMed, PG Dip (HSE); A D Marais, ${ }^{2} \mathrm{MB}$ ChB, FCP

\begin{abstract}
${ }^{1}$ Department of Chemical Pathology, National Health Laboratory Service, Pretoria; and Department of Chemical Pathology, Sefako Makgatho Health Sciences University, Pretoria, South Africa

${ }^{2}$ Department of Chemical Pathology, National Health Laboratory Service, Cape Town; Lipidology Research Unit, Faculty of Health Sciences, University of Cape Town; and Lipid Clinic, Groote Schuur Hospital, Cape Town, South Africa
\end{abstract}

Corresponding author: A A Khine (ayeaye.khine@smu.ac.za)

\begin{abstract}
Background. The prevalence of cardiovascular disease is projected to be $38.7 \%$ for the USA in 2020, including coronary heart disease at $8.6 \%$ and stroke at 3.6\%. In South Africa (SA), premature deaths due to heart and blood vessel diseases in people of working age (35 - 64 years) have been predicted to increase by $41 \%$ between 2007 and 2030, with enormous negative economic impact. Atherosclerosis underlies much of the pathogenesis, which involves risk factors including dyslipidaemia. Secondary dyslipidaemia associated with diabetes mellitus, hypothyroidism, chronic renal disease, cholestasis, nephrotic syndrome, alcohol excess, drugs such as thiazide diuretics and antiretroviral agents may respond to treatment of underlying causes, but residual dyslipidaemia may in such cases be due to primary disorders of metabolism. Primary dyslipidaemias are uncommon and to a large extent underdiagnosed, especially in the black population of SA, reflecting a lack of clinical and laboratory awareness or expertise. Specific diagnoses enable effective intervention in the patients as well as the families.

Objective. To assess the burden and prevalence of dyslipidaemia in the SA black population at Dr George Mukhari Hospital in the north region of Gauteng.

Method. A retrospective data analysis of 12-month lipid profiles comprising triglyceride (TG), total cholesterol (TC), high-density lipoprotein cholesterol and directly measured low-density lipoprotein (LDL) cholesterol (LDLC).

Results. There were 24656 requests for 6348 patients. The lipid cut-off levels were somewhat arbitrary but were based on the commonly used decision-making levels in the treatment guidelines. Severe hypercholesterolaemia ( $>7 \mathrm{mmol} / \mathrm{L}$ ) was seen in $299(4.7 \%)$ patients and extreme hypercholesterolaemia $(>12 \mathrm{mmol} / \mathrm{L})$ was seen in $30(0.5 \%)$ patients. LDLC $(>5 \mathrm{mmol} / \mathrm{L})$ occurred in $80(1.3 \%)$ patients and $>10 \mathrm{mmol} / \mathrm{L}$ in $19(0.3 \%)$ patients. A predominant triglyceride problem was seen in $578(9.1 \%)$ patients with TG $(>2 \mathrm{mmol} / \mathrm{L})$ and TC $(<5 \mathrm{mmol} / \mathrm{L})$, whereas moderate hypertriglyceridaemia $(>5 \mathrm{mmol} / \mathrm{L})$ was present in $113(1.8 \%)$ patients, and more severe hypertriglyceridaemia $(>10 \mathrm{mmol} / \mathrm{L})$ in $10(0.2 \%)$. TC $(>5 \mathrm{mmol} / \mathrm{L})$ with LDL $(>3 \mathrm{mmol} / \mathrm{L})$ but TG in the normal range was seen in $369(5.8 \%)$ patients, indicating a cholesterol-predominant problem. In contrast, LDLC $(>3 \mathrm{mmol} / \mathrm{L})$ and TG $(>1.7 \mathrm{mmol} / \mathrm{L})$ was seen in $249(3.87 \%)$ representing mixed hyperlipidaemia. Paediatric patients with severe dyslipidaemia mostly suffered from nephrotic syndrome.

Conclusion. A significant burden and a high prevalence of dyslipidaemias were present in adults in whom a monogenic disorder should be considered. The extent and severity of dyslipidaemia justify a special clinic and laboratory to ensure accurate diagnosis with effective intervention for patients and their families.
\end{abstract}

S Afr Med J 2016;106(7):724-729. DOI:10.7196/SAMJ.2016.v106i7.10337

The American Heart Association predicted the rise in the prevalence of cardiovascular disease as $38.7 \%$ by 2020 , where the coronary heart disease would rise for $8.6 \%$ and stroke for 3.6\% ${ }^{[1]}$ In South Africa (SA), Liberty Life Insurance group has forecast the premature deaths due to heart and blood vessel diseases in people of working age (35 - 64 years) to increase by $41 \%$ between 2007 and 2030, with a warning of enormous negative economic impact. ${ }^{[2]}$ Locally, an increased awareness of cardiovascular disease at the Dr George Mukhari referral hospital has led to more requests for plasma lipid profiles comprising fasting triglyceride (TG), total cholesterol (TC), high-density lipoprotein (HDL) cholesterol (HDLC) and low-density lipoprotein (LDL) cholesterol (LDLC). In 2013, 18234 lipid profiles from 7255 patients were analysed compared with 24656 requests for 6348 patients in 2014. The 35\% increase occurred despite opening a new antiretroviral (ARV) clinic in the neighbourhood, which reduced patient flow at the tertiary hospital, and the introduction of electronic gatekeeping. Requests were in response to patients' history of early death among first-degree relatives due to heart disease and stroke, ${ }^{[3]}$ and cardiovascular risk suggested by obesity, metabolic syndrome, smoking, sedentary lifestyle, lack of exercise and stressful living. Genetic disorders in lipoprotein metabolic pathways generally have a greater impact on risk and typically display more severe and/ or persistent lipid abnormalities after treating the secondary factors. ${ }^{[4,5]}$ Cascade testing of the family is advised. ${ }^{[6]}$ Admixture of primary and secondary causes is especially evident in Fredrickson hyperlipidaemia types III, IV and V, where predisposing variant genes are stressed by diet, obesity with insulin resistance, hormonal derangements and alcohol intake. In SA, at least three low-density lipoprotein receptor (LDLR) mutations are known in Afrikaans-speaking whites, one in Jewish people from Eastern Europe and one in Indians of Gujerati descent. ${ }^{[7,8]}$ Familial hypercholesterolaemia (FH) is mostly due to a pathogenic mutation in one of three genes (LDLR, apolipoprotein B (apoB) or proprotein convertase subtilisin/kexin type 9 ). FH is relatively common (prevalence 1:200 - 1:500) and is therefore the most important monogenic disorder of lipoprotein metabolism. It exists as either heterozygous, where only one allele of the gene involved is mutated and the other allele is normal, or homozygous, where both alleles are abnormal. Persons with untreated 
homozygous $\mathrm{FH}$ are at an approximately 20 -fold increased risk for coronary heart disease (CHD), which usually presents in their early 20s. Heterozygous $\mathrm{FH}$ is more common (no data for SA yet) and untreated men have a $50 \%$ risk of having a coronary event by age 50 years; untreated women are at a 30\% risk by age 60 years. ${ }^{[9]} \mathrm{FH}$ has not been fully investigated in all SA population groups. The commonly held view that disorders of lipoprotein metabolism are absent in the SA black population needs to be dispelled, as it detracts from the recognition of disorders imparting high, but remediable, risk; especially if the previous (rural) lifestyle was protective against atherosclerosis as urbanisation increases cardiovascular diseases. A founder effect may exist in the black population for a six-nucleotide deletion. ${ }^{[9]}$ The homozygous FH phenotype has been described in a patient with LDLR mutations and autosomal recessive hypercholesterolaemia. ${ }^{[10]}$ Dysbetalipoproteinaemia seems common in black patients at an SA lipid clinic. ${ }^{[1]}$ Other than apolipoprotein E (apoE2) allele $2 / 2$ homozygosity accounting for dysbetalipoproteinaemia, De Villiers et al. ${ }^{[12]}$ found that the apoE Arg145Cys mutation was present in patients of mixed ancestry, whites and more commonly in blacks in Cape Town. The mode of inheritance was autosomal dominant with delayed and incomplete penetrance. ${ }^{[12]}$

Most dyslipidaemias can be diagnosed by the lipid profile, but subtler dyslipidaemias in which triglyceride-rich particles such as very-low-density lipoprotein (VLDL) and intermediate-density lipoprotein accumulate, or the more atherogenic small dense LDL, are found to require more sophisticated investigations. A non-denaturing gradient gel electrophoresis method was shown to be practical, cost-effective and a good diagnostic test for dysbetalipoproteinaemia. ${ }^{[13,14]}$

The Dr George Mukhari Hospital is a tertiary referral hospital drawing patients from northern Gauteng, North West and Limpopo provinces. It is affiliated to Sefako Makgatho Health Sciences University (previously Medunsa). Most patients were indigenous black Africans. To study the prevalence of lipid abnormalities and recognition of monogenic disorders of lipoprotein metabolism in this population, an audit of the lipid requests was performed at this hospital.

\section{Objectives}

To assess the burden of lipid profile abnormalities and possible primary or familial dyslipidaemias at $\mathrm{Dr}$ George Mukhari Hospital, northern Gauteng, SA.

\section{Methods}

Analyses of plasma or serum were done in an accredited laboratory with commercially available enzymatic assays for TG and TC; homogenous immunoassay assays for HDLC and LDLC (direct) were performed with Synchron series reagent kits using a DXc automated analyser (Beckman Coulter, USA) The laboratory practised quality control to ensure that data were consistent and comparable with other laboratories. Samples were analysed in the fasted state, except in children.

A cross-sectional audit was done of 12 months of data (1 January - 31 December 2014) extracted from the laboratory information system. Clinical files of patients with severe lipid abnormalities were viewed for clinical details and treatment and data were captured on Microsoft Excel (Microsoft Corporation, USA) without revealing identity. Adults mostly had only one test whereas in paediatric patients lipid profiles were often done 3-monthly. The numbers of patients with various dyslipidaemias were derived from the master database. Hypercholesterolaemia was taken as $>5 \mathrm{mmol} / \mathrm{L}$, severe as $>7 \mathrm{mmol} / \mathrm{L}$ ) and extreme as $>12 \mathrm{mmol} / \mathrm{L}$ ); the commensurate LDLC levels were $3 \mathrm{mmol} / \mathrm{L}$, $4 \mathrm{mmol} / \mathrm{L}, 5 \mathrm{mmol} / \mathrm{L}$ and $6 \mathrm{mmol} / \mathrm{L}$ taking a stepwise approach of classifying the severity. Hypertriglyceridaemia was taken as mild ( $>2 \mathrm{mmol} / \mathrm{L}$ ), moderate $(>5 \mathrm{mmol} / \mathrm{L})$ and severe $(>10 \mathrm{mmol} / \mathrm{L})$. These are convenient for clinical decision-making limits.

Patient identities were kept confidential. Relevant patients' files were reviewed with the permission from the hospital manager.

\section{Results}

There were 24656 lipid profiles for 6348 patients over 12 months. Table 1 summarises the mean, standard deviation (SD), median and range (minimum; maximum) for each lipid parameter extracted. The distribution of each component of the lipid profile is shown in Figs 1 - 4.

The data were analysed separately for adult and paediatric patients. In addition to the information on the request forms and patients' files, locations (outpatient departments, clinics and wards) at the hospital from which the patient was referred also indicated chronic diseases, such as diabetes, HIV treated with ARVs, endocrine conditions such as hypothyroidism, and paediatric high care (nephrotic syndrome) and cardiac high care as well as cardiology outpatients.

Table 2 summarises significantly deranged lipid levels and percentage of patients affected out of the total of 6348 with clinical diagnoses indicated on the laboratory request forms. TC $(<5 \mathrm{mmol} / \mathrm{L})$ with TG $(<1.7 \mathrm{mmol} / \mathrm{L})$ (better lipid levels) was present in 3574 (56.3\%). The desired target of LDLC for primary prevention
Table 1. Distribution of lipid parameters in the study population

\begin{tabular}{lllll}
\hline & TC $(\mathbf{m m o l} / \mathbf{L})$ & LDLC $(\mathbf{m m o l} / \mathbf{L})$ & TG $(\mathbf{m m o l} / \mathbf{L})$ & HDLC $(\mathbf{m m o l} / \mathbf{L})$ \\
\hline Mean $(\mathrm{SD})$ & $4.42(1.66)$ & $2.32(1.18)$ & $1.50(1.17)$ & $1.13(0.49)$ \\
Median & 4.28 & 2.27 & 1.18 & 1.14 \\
Minimum & 0.38 & 0.07 & 0.10 & 0.13 \\
Maximum & 23.00 & 12.77 & 13.47 & 4.50
\end{tabular}

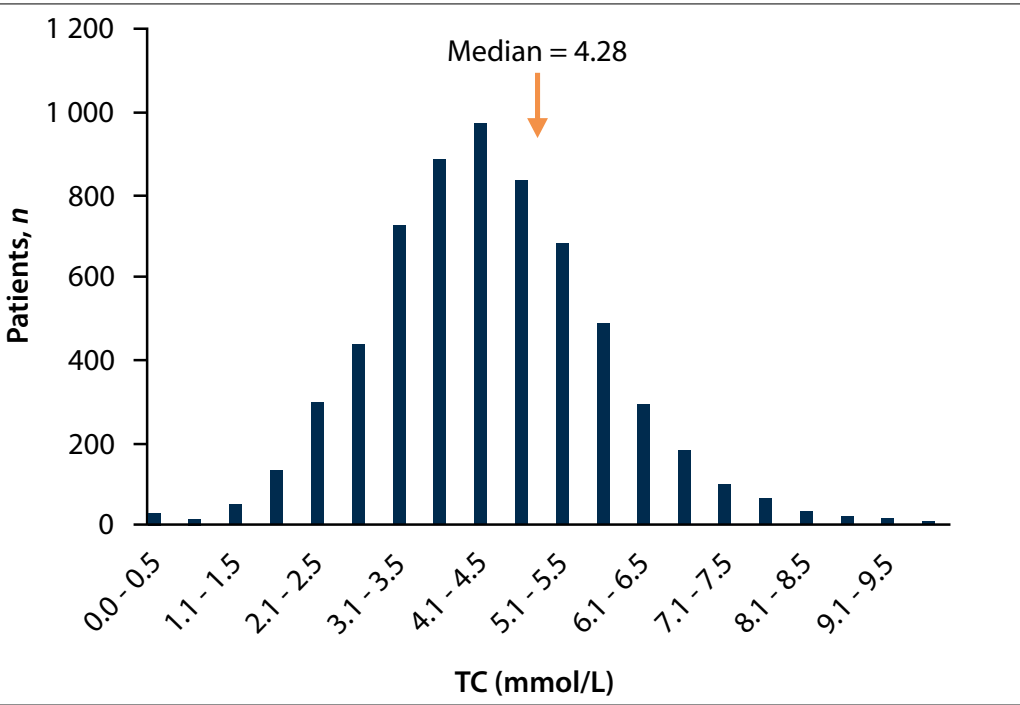

Fig. 1. Total cholesterol distribution (results abridged). 
of atherosclerosis ( $>3 \mathrm{mmol} / \mathrm{L}$ ) combined with a normal HDL ( $>2 \mathrm{mmol} / \mathrm{L}$ ) was seen in $85(1.2 \%)$ patients, indicating isolated LDL problem, while 99 (1.6\%) patients had additional higher risk owing to low HDLC $(<0.8 \mathrm{mmol} / \mathrm{L})$ over and above their LDL being $>3 \mathrm{mmol} / \mathrm{L}$, indicating both $\mathrm{LDL}$ and HDL problems. Highlighting the cholesterolpredominant problem, TC ( $>6 \mathrm{mmol} / \mathrm{L})$ with LDL $(>4 \mathrm{mmol} / \mathrm{L})$ with $\mathrm{TG}$ in the normal range $(<1.7 \mathrm{mmol} / \mathrm{L})$ was seen in 176 $(2.8 \%)$ patients. To indicate a triglyceridepredominant problem, TC $(<5 \mathrm{mmol} / \mathrm{L})$ with TG (>2.0 mmol/L) was seen in $602(9.5 \%)$ patients. In another group, TC $(>6.0 \mathrm{mmol} / \mathrm{L})$, LDL $(>4 \mathrm{mmol} / \mathrm{L})$ and TG $(>2.0 \mathrm{mmol} / \mathrm{L})$ were seen in 322 (5.1\%), representing mixed hyperlipidaemia and imposing cardiovascular risk. Hypercholesterolaemia from $5 \mathrm{mmol} / \mathrm{L}$ to $7 \mathrm{mmol} / \mathrm{L}$ was seen in $1659(26.1 \%)$ patients. Severe hypercholesterolaemia was seen in 315 patients (5.0\%) and extreme hypercholesterolaemia was seen in $33(0.5 \%)$ patients. These cases may indicate underlying monogenic disorders as well as secondary causes. While LDLC ( $>5 \mathrm{mmol} / \mathrm{L})$ is frequently taken as a cut-point for $\mathrm{FH}$, a stricter cut-off of $>6 \mathrm{mmol} / \mathrm{L}$ was present in $78(1.2 \%)$ patients and $>8 \mathrm{mmol} / \mathrm{L}$ in $19(0.3 \%)$ patients. Hypertriglyceridaemia
(>5 mmol/L) was present in $113(1.8 \%)$ patients and $>10 \mathrm{mmol} / \mathrm{L}$ in $10(0.2 \%)$, signalling a risk for pancreatitis. HDLC $(<0.8 \mathrm{mmol} / \mathrm{L})$ was seen in $1341(21.1 \%)$ patients and hyperalphalipoproteinaemia (HDLC >2 mmol/L) was seen in 248 (3.9\%) patients.

Table 3 provides the information on patients in whom secondary dyslipidaemia was excluded, as well as those on thiazides.

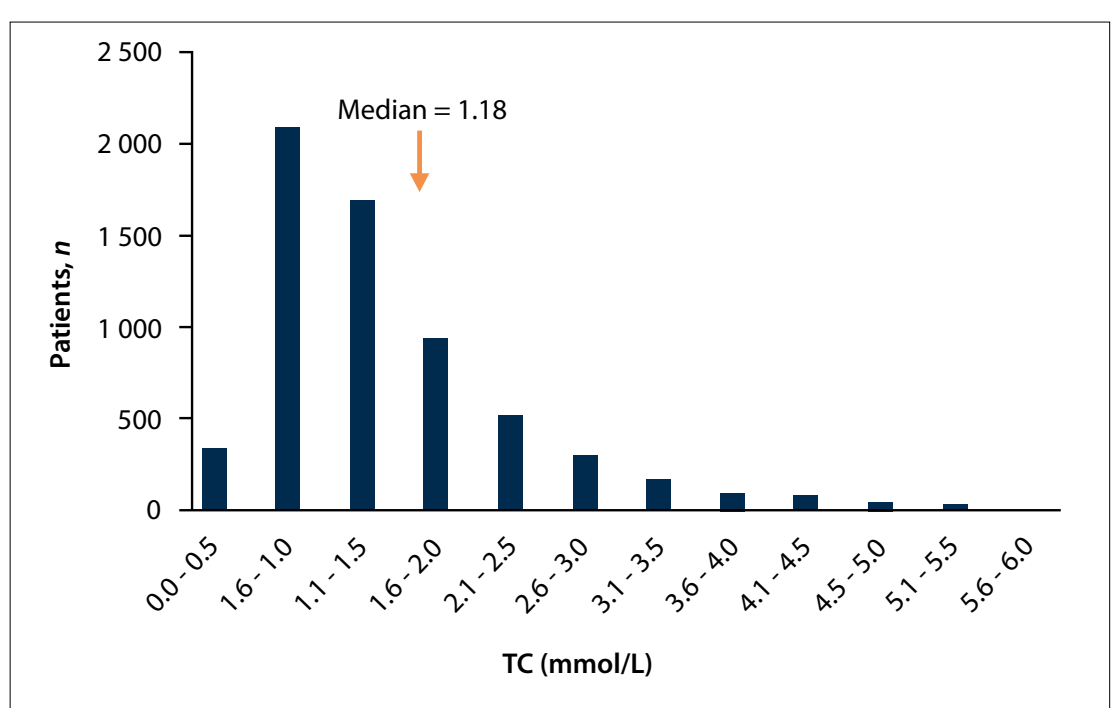

Fig. 2. Triglyceride distribution (results abridged).
The thiazides probably increase LDLC by 1 $2 \%$ and therefore any TC $>7 \mathrm{mmol} / \mathrm{L}$ should still be counted as pathological. ${ }^{[15,16]}$ Patients treated with simvastatin without initial lipid profiles in the laboratory information system had estimated levels by the calculation based on the LDLC lowering efficacy in African Americans. Adjusted LDLC = current LDLC $+26 \%( \pm 3 \%)$ for simvastatin $20 \mathrm{mg} /$ day dose and $+21 \%( \pm 1 \%)$ for simvastatin $10 \mathrm{mg}$ once

Table 2. Significantly deranged lipid levels and percentage of patients affected out of the total of 6348 with clinical diagnoses (Dx) indicated on the laboratory request form $s^{\star}$

\begin{tabular}{|c|c|c|c|c|c|c|c|c|c|}
\hline $\begin{array}{l}\text { Lipid level } \\
(\mathrm{mmol} / \mathrm{L})\end{array}$ & Patients, $n(\%)$ & & & & & & & & \\
\hline $\mathrm{TC}>5$ & $1961(30.9)$ & & & & & & & & \\
\hline TC $5-7$ & $1659(26.1)$ & & & & & & & & \\
\hline $\mathrm{TC}>7$ & $315(5.0)$ & & & & & & & & \\
\hline $\mathrm{TC}>12$ & $33(0.5)$ & & & & & & & & \\
\hline $\mathrm{TG}>5$ & $113(1.8)$ & & & & & & & & \\
\hline $\mathrm{TG}>10$ & $10(0.2)$ & & & & & & & & \\
\hline LDLC $>6$ & $78(1.2)$ & & & & & & & & \\
\hline LDLC $>8$ & $19(0.3)$ & & & & & & & & \\
\hline HDLC $<0.8$ & $1341(21.1)$ & & & & & & & & \\
\hline HDLC $>2$ & $254(4.0)$ & & & & & & & & \\
\hline Lipid level (mmol/L) & Patients, $n(\%)$ & Diabetes (\%) & CKD (\%) & $\begin{array}{l}\text { Liver } \\
\text { Ds (\%) }\end{array}$ & Hypertension (\%) & $\begin{array}{l}\text { IHD/ } \\
\text { CABG (\%) }\end{array}$ & NS (\%) & ARV (\%) & $\begin{array}{l}\text { No Dx } \\
\text { indicated (\%) }\end{array}$ \\
\hline $\mathrm{TC}<5, \mathrm{TG}<1.7$ & $3574(56.3)$ & \multicolumn{8}{|c|}{ Diagnosis not reviewed because these lipid levels are generally acceptable } \\
\hline $\mathrm{TC}>5, \mathrm{LDL}>3, \mathrm{TG}<1.7$ & $777(12.2)$ & 30 & 5 & 0 & 30 & 10 & 10 & 10 & 5 \\
\hline $\mathrm{TC}>6, \mathrm{LDL}>3, \mathrm{TG}>2.0$ & $322(5.1)$ & 45 & 10 & 1 & 30 & 10 & 4 & 0 & 0 \\
\hline $\mathrm{TC}<5, \mathrm{TG}>2.0$ & $602(9.5)$ & 20 & 20 & 0 & 5 & 0 & 15 & 5 & 35 \\
\hline LDLC $>3$, HDLC $<0.8$ & $99(1.6)$ & 25 & 12 & 3 & 20 & 20 & 20 & 0 & 0 \\
\hline LDLC $>3$, HDLC $>2$ & $85(1.3)$ & \multicolumn{8}{|c|}{$\begin{array}{l}\text { These patients overlapped with the group of TC }>5 \mathrm{mmol} / \mathrm{L}, \mathrm{LDL}>3 \mathrm{mmol} / \mathrm{L} \text { and } \mathrm{TG}<1.7 \mathrm{mmol} / \mathrm{L} \text {, so their } \\
\text { diagnoses are not mentioned separately here }\end{array}$} \\
\hline
\end{tabular}


Table 3. Demography and clinical profile with the lipid levels* in significantly affected $(n=19)$ patients

\begin{tabular}{|c|c|c|c|c|c|c|c|c|c|c|c|}
\hline Patient No. & Age (yr) & Gender & Ethnicity & TC & LDLC & $\begin{array}{l}\text { Estimated initial } \\
\text { LDLC, range }\end{array}$ & TG & HDLC & $\begin{array}{l}\text { Non- } \\
\text { HDLC }\end{array}$ & Diagnosis & Medication \\
\hline 1 & 55 & $\mathrm{~F}$ & SW & 8.4 & 6.5 & $7.94-8.44$ & 1.27 & 1.66 & 6.74 & IHD & Sim $20 \mathrm{mg}$ \\
\hline 2 & 57 & $\mathrm{~F}$ & S & 8.6 & 7.0 & $8.59-9.08$ & 1.63 & 1.36 & 7.24 & CABG & Sim $20 \mathrm{mg}$ \\
\hline 3 & 61 & M & SW & 6.3 & 4.7 & $6.93-7.36$ & 1.22 & 1.55 & 4.75 & AS & $\operatorname{Sim} 20 \mathrm{mg}+\mathrm{AHT}$ \\
\hline 4 & 65 & $\mathrm{~F}$ & SW & 6.9 & 4.9 & $5.99-6.36$ & 0.71 & 2.17 & 4.73 & AMI & Sim $20 \mathrm{mg}$ \\
\hline 5 & 26 & $\mathrm{~F}$ & $\mathrm{~V}$ & 6.6 & 4.8 & No statins & 1.12 & 1.73 & 4.87 & CCF/PTB & None \\
\hline 6 & 64 & M & S & 7.4 & 5.9 & $8.7-9.24$ & 1.54 & 1.23 & 6.17 & AMI & Sim $20 \mathrm{mg}$ \\
\hline 7 & 59 & $\mathrm{~F}$ & S & 6.1 & 4.1 & $5.01-5.32$ & 1.37 & 1.61 & 4.49 & HLP & Sim $20 \mathrm{mg}$ \\
\hline 8 & 50 & $\mathrm{~F}$ & $\mathrm{P}$ & 7.1 & 5.6 & $6.84-7.27$ & 1.31 & 1.20 & 5.90 & AS \& IHD & Sim $20 \mathrm{mg}$ \\
\hline 9 & 70 & $\mathrm{~F}$ & $\mathrm{P}$ & 9.6 & 7.3 & No statins & 1.29 & 1.45 & 8.15 & IHD/HHF & AHT \\
\hline 10 & 37 & M & S & 6.2 & 4.6 & $5.62-5.97$ & 0.87 & 1.28 & 4.92 & AP & Sim $20 \mathrm{mg}$ \\
\hline 11 & 67 & $\mathrm{~F}$ & SW & 9.1 & 7.0 & No statins & 1.67 & 1.84 & 7.26 & $\mathrm{AP} / \mathrm{HPT}$ & AHT \\
\hline 12 & 84 & $\mathrm{~F}$ & SW & 7.6 & 4.4 & No statins & 1.31 & 1.19 & 6.41 & CCF/LVD & Amiloride $5 \mathrm{mg}$ \\
\hline 13 & 50 & $\mathrm{~F}$ & SW & 6.6 & 5.0 & $6.11-6.49$ & 1.21 & 1.34 & 5.26 & HLP & Sim $20 \mathrm{mg}$ \\
\hline 14 & 21 & M & SW & 6.8 & 5.4 & No statins & 0.66 & 1.52 & 5.28 & PHT + smoking & Digoxin \\
\hline 15 & 68 & $\mathrm{~F}$ & SW & 6.5 & 4.8 & $5.87-6.23$ & 1.28 & 1.39 & 5.11 & ACS & Sim $20 \mathrm{mg}$ \\
\hline 16 & 50 & $\mathrm{~F}$ & $\mathrm{P}$ & 6.47 & 4.8 & $5.87-6.23$ & 0.68 & 1.66 & 4.81 & AMI & Sim $20 \mathrm{mg}$ \\
\hline 17 & 60 & M & $\mathrm{P}$ & 6.16 & 5.66 & No statins & 0.96 & 1.23 & 4.93 & $\mathrm{CCF}$ & Amiloride, digoxin \\
\hline 18 & 51 & $\mathrm{~F}$ & S & 6.86 & 5.12 & $6.26-6.64$ & 0.86 & 2.59 & 4.27 & AP & Sim $20 \mathrm{mg}$ \\
\hline 19 & 55 & $\mathrm{~F}$ & S & 6.21 & 4.88 & $5.96-6.33$ & 1.52 & 0.86 & 5.35 & IHD & Sim $20 \mathrm{mg}$ \\
\hline
\end{tabular}

a day (od) (taken from pravastatin $10 \mathrm{mg}$ od dose from the reference cited, as there was no adjustment for simvastatin $10 \mathrm{mg}$ od) ${ }^{[17]}$ The ratio of TC/HDLC or LDLC/HDLC may be used to assess risk when dealing with moderate dyslipidaemia. ${ }^{[18]}$ In addition, non-HDLC was also calculated as a guide to atherogenicity. ${ }^{[19]}$

A total of 555 requests came from 148 patients in the paediatric cohort (average 3 - 4 tests per patient in 12 months), almost all from inpatients. Table 4 presents the proportion of paediatric patients with lipid profiles significantly elevated. Eighteen out of $148(12 \%)$ had TC $>6 \mathrm{mmol} / \mathrm{L}$ and $49(33.1 \%)$ patients had LDLC $>3 \mathrm{mmol} / \mathrm{L}$, while 10 (7\%) patients had LDLC $>4 \mathrm{mmol} / \mathrm{L}$ and 31 (21\%) patients had LDLC $>5 \mathrm{mmol} / \mathrm{L}$. Hypertriglyceridaemia of $>1.7 \mathrm{mmol} / \mathrm{L}$ was present in 66 patients $(44.6 \%),>2 \mathrm{mmol} / \mathrm{L}$ in $59(40 \%)$ and $>5 \mathrm{mmol} / \mathrm{L}$ in $15(10.1 \%)$.

Clinical files of 46 paediatric patients ( 31 with LDLC $>5 \mathrm{mmol} / \mathrm{L}$ and TG $>5 \mathrm{mmol} / \mathrm{L}$ ) were reviewed (Table 4). Of these, $23(50 \%)$ were diabetic with glycated haemoglobin ranging from $7 \%$ to $10 \%$, 15 (32\%) patients had nephrotic syndrome, of whom 5 had severe hypercholesterolaemia $(7.5-14.4 \mathrm{mmol} / \mathrm{L})$. Eight (17\%) were HIV patients on protease inhibitor treatment.

\section{Discussion}

This study revealed an awareness of dyslipidaemia and cardiovascular risk with comorbidities in adult and paediatric patients. While secondary causes were prominent in children, a large portion of adults had moderate dyslipidaemias associated with other risk factors such as hypertension and diabetes, and drugs such as thiazides could have contributed. Severe hyperlipidaemia suggestive of monogenic disorders of lipoprotein metabolism was likely to be present in a

$\begin{aligned} & \text { Table 4. Numbers and percentages of paediatric patients } \\
& \text { affected, according to various lipid cut-off levels }\end{aligned}$
\begin{tabular}{lll}
\hline Patients & Lipid level (mmol/L) & $\boldsymbol{n}(\%)$ \\
\hline With high TC & $>6$ & $18(12.0)$ \\
With high LDL & $>3$ & $49(33.1)$ \\
& $>4$ & $10(7.0)$ \\
& $>5$ & $31(21.0)$ \\
With high TG & $>1.7$ & $66(44.6)$ \\
& $>2$ & $59(40.0)$ \\
& $>5$ & $15(10.1)$
\end{tabular}

small proportion but was not specifically considered in the notes. Patients with abnormal lipid levels were not worked up using lipid electrophoresis on agarose gel or polyacrylamide gel in order to look for specific types of hyperlipidaemias. Moreover, additional tests such as lipoprotein (a), which poses independent risk for cardiovascular complications, were not evaluated. This has a negative impact on patient management as the significant hyperlipidaemias could, to some extent, be affected or underplayed by genetic mutations or polymorphisms. If these were detected by proper work-up, both patient and family could benefit.

In the distribution graphs (Figs 1 - 4), the HDLC displayed a normal distribution, and TC and LDLC had some patients with strikingly low values that detracted from a normal distribution. 


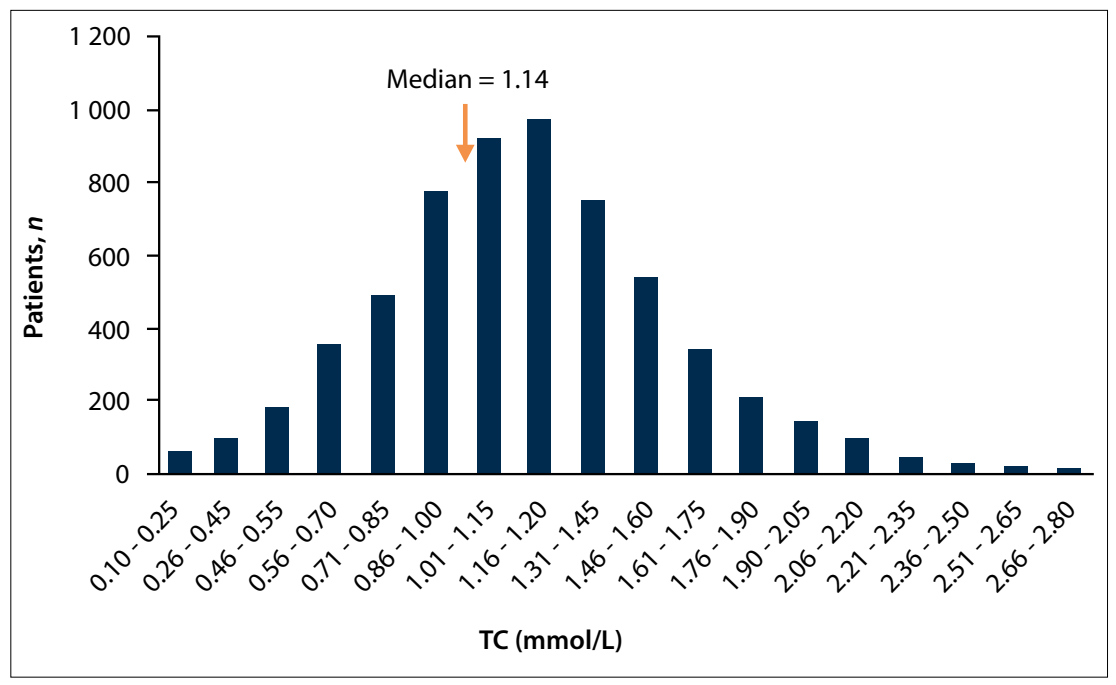

Fig. 3. HDL distribution (results abridged).

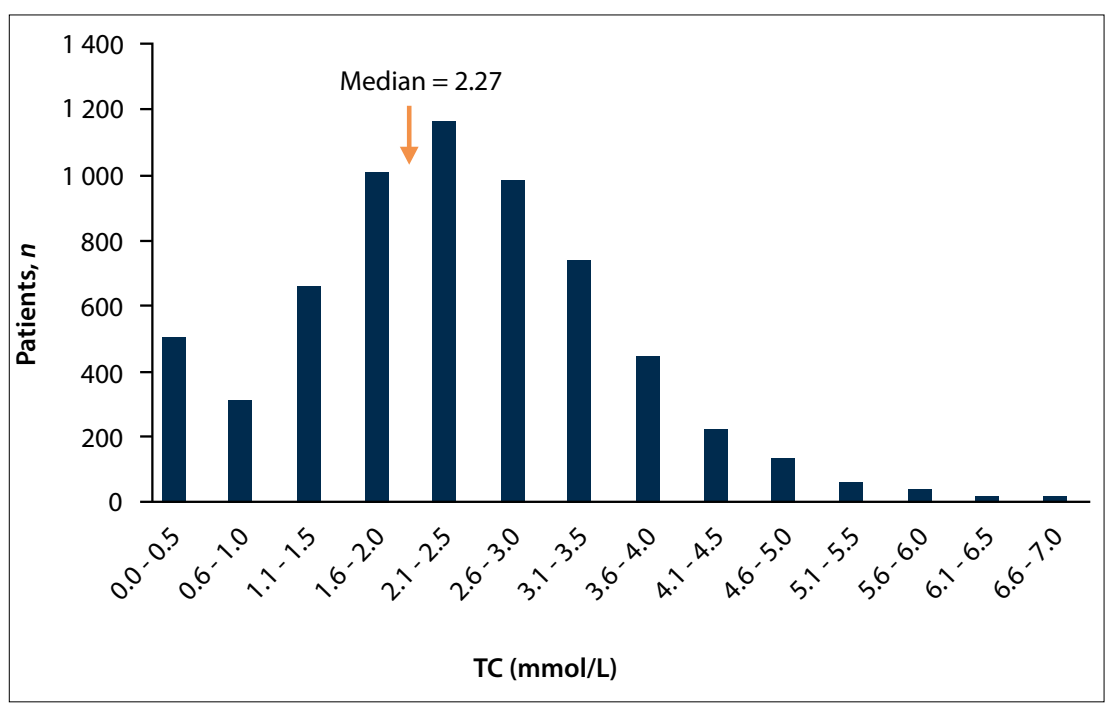

Fig. 4. LDL distribution (results abridged).

Thirty randomly selected patient files with TC $<3 \mathrm{mmol} / \mathrm{L}$ and $\mathrm{LDL}<2 \mathrm{mmol} / \mathrm{L}$ were assessed and it was found that the bloods were taken for lipid levels during acute illness, such as acute myocardial infarction, which could represent apolipoproteins affected by negative acute phase reaction. Ten patients with lower levels of TC and TG (taken as a sample from TC $<3 \mathrm{mmol} / \mathrm{L}$ and $\mathrm{TG}<1 \mathrm{mmol} / \mathrm{L}$ ) were also found to have suffered from chronic cardiac failure with possible cardiac cirrhosis, which could have contributed to lower secretion of apoB 100. Despite these, TG concentrations, not corrected for background glycerol, also showed the typical skewed distribution towards higher values that could be attributed to patients with uncontrolled diabetes, chronic kidney disease and nephrotic syndrome. Upon closer examination of the combination of various lipid parameters at the relevant medical decision limits
(Table 2), there was a large number of patients with TC $>5 \mathrm{mmol} / \mathrm{L}$, the level at which cholesterol-lowering therapy should have been initiated. Patients whose TC $>7.0 \mathrm{mmol} / \mathrm{L}$, which could be suggestive of underlying heterozygous $\mathrm{FH}$, are at a much higher risk of coronary complications; this category justifies medication as well as lifestyle changes. ${ }^{[5]} \mathrm{TC}>5 \mathrm{mmol} / \mathrm{L}$ with $\mathrm{LDL}>3 \mathrm{mmol} / \mathrm{L}$ and $\mathrm{TG}<1.7 \mathrm{mmol} / \mathrm{L}$ was seen in $777(12.2 \%)$, and this may represent polygenic hypercholesterolaemia, while $\mathrm{TC}>6 \mathrm{mmol} / \mathrm{L}, \mathrm{LDL}>3 \mathrm{mmol} / \mathrm{L}$ and $\mathrm{TG}>2.0 \mathrm{mmol} / \mathrm{L}$ may reflect type IIb hyperlipidaemia as seen in $322(5.1 \%)$ patients. TC $<5 \mathrm{mmol} / \mathrm{L}$ with TG $>2 \mathrm{mmol} / \mathrm{L}$ was seen in $602(9.5 \%)$, and could indicate chronic disorders of lifestyle, including obesity, metabolic syndrome or medications. Not surprisingly, the patients with patterns of moderate dyslipidaemia had a relatively high prevalence of monogenic disorders.
After evaluating the patient files, patients with severe dyslipidaemias diagnosed with ischaemic heart disease, hypertension and coronary heart disease were analysed. The adjusted initial LDLC levels of patients already on statins indicated possible underlying genetic disorders of LDL clearance. This subset of patients had no contributions to dyslipidaemias from secondary causes, and as mentioned before, patients with hypertension and on thiazide treatment are using a standard dose of $12.5 \mathrm{mg}$ od, and at this level its effect on hyperlipidaemia is modest if not minimal. ${ }^{[18]}$ The absence of causes of secondary dyslipidaemia in this severely hypercholesterolaemic group suggests either polygenic disorder, in which multiple polymorphisms of genes are involved in increased production of LDL, or reduced clearance of LDL due to underlying heterozygous $\mathrm{FH}^{[10]}$

This study also revealed $637(9.98 \%)$ patients who presented with cardiac ischaemia and coronary heart disease - not shown in the tables, but obtained from the original data extract by filtering based on the hospital locations where such patients are exclusively cared for. In this population, striking dyslipidaemias without comorbidities were seen and may suggest primary dyslipidaemia, including $\mathrm{FH}$. The ratio of TC/HDLC or LDLC/HDLC may be used to assess risk when dealing with moderate dyslipidaemia. ${ }^{[18]} \mathrm{A}$ ratio of $\mathrm{TC} /$ HDLC >4 was seen in 2475 patients, and a ratio of LDLC/HDLC >2 was seen in 2912 patients. Non-HDLC $>4 \mathrm{mmol} / \mathrm{L}$ (indicative of cardiovascular risk) was seen in 1567 patients. ${ }^{[19]}$ A ratio of TC/TG >2.0 was observed in 4219 patients, and in the study of Blom et al. ${ }^{[20]}$ such a ratio was seen in patients with dysbetalipoproteinaemia, although the ratio can be highly variable. The Friedewald calculation permits derivation of LDLC when TG is $<4.5 \mathrm{mmol} / \mathrm{L}$, except in dysbetalipoproteinaemia. In 6187 (97.5\%) patients whose TG was $<4.5 \mathrm{mmol} / \mathrm{L}$ (not shown in the tables), the calculated LDLC exceeded the directly measured LDLC by $>1 \mathrm{mmol} / \mathrm{L}$ in 2737 (43.11\%) patients; this may suggest dysbetalipoproteinaemia (type III hyperlipidaemia). ${ }^{[21]}$ Severe hypertriglyceridaemia compatible with Fredrickson type $\mathrm{V}$ was also noted, albeit in small numbers.

\section{Conclusion}

These findings illustrate that various types of primary and secondary dyslipidaemias are seen in adult black patients at this hospital. Regarding paediatric patients, the majority presented with severe dyslipidaemia 
owing to underlying nephrotic syndrome, type I diabetes and ARV therapy, although unfavourable underlying genetic variations could not be excluded. The high prevalence of dyslipidaemias may herald cardiovascular disease in a population known to be undergoing lifestyle changes with urbanisation. Unlike the other comorbidities, hypertension does not affect the lipid profile per se but promotes atherosclerosis in a possible positive feedback loop. Unfavourable changes of TC, VLDLC, LDLC/HDLC and HDLC/TC during thiazide treatment, especially at the low dosage of $12.5 \mathrm{mg}$ od may only be a small contributor, but to obtain a more favourable lipid profile, consideration may need to be given to lipid-neutral antihypertensive agents such as angiotensinconverting enzyme inhibitors or calcium channel blockers. ${ }^{[18]}$

Ideally, further investigation should be undertaken to determine the cause(s) of the dyslipidaemias, by characterising the lipoprotein subsets (electrophoresis) and proceeding to appropriate genetic testing, to expedite cascade testing as well as to provide more accurate counselling about heritability. The information and interpretation of data in this study justify the establishment of a lipid clinic dedicated to work-up dyslipidaemias along with a laboratory that can perform more specialised tests.

\footnotetext{
References

1. Heidenreich PA, Trogdon JG, Khavjou OA, et al. Forecasting the future of cardiovascular disease in the United States: A policy statement from the American Heart Association. Circulation 2011;123(8):933-944 DOI:10.1161/CIR.0b013e31820a55f5

2. Liberty Insurance Group South Africa. Heart Disease Fact Sheet. Liberty Insurance Group South Africa 2004.

3. Klug EQ, Raal FJ, Marais AD, et al. South African dyslipidaemia guideline consensus statement. S Afr Fam Pract 2015;57(2):23-31. DOI:10.1080/20786204.2013.10874296

4. Steyn K, Jooste PL, Bourne L, et al. Risk factors for coronary heart disease in the black population of the Cape Peninsula. The BRISK study S Afr Med J 1991:79(8):480-485.
}

5. Shoulders CC, Jones EL, Naoumova RP. Genetics of familial combined hyperlipidemia and risk of coronary heart disease. Hum Mol Genet 2004;13(1):R149-R160. DOI:10.1093/hmg/ddh069

6. Marais AD. Hereditary hyperlipidaemias: Clinical findings and sub-typings. Cardiovasc I S Afr 1994:4(Suppl):S7-S9.
6. Marais AD. Heredita

7. Rubinsztein DC, van der Westhuyzen DR, Coetzee GA. Monogenic primary hypercholesterolaemia in South Rubinsztein DC, van der Westhuyzen DR,
Africa. S Afr Med J 1994;84(6):339-344.

8. Blom DJ. Familial hypercholesterolaemia. S Afr Fam Pract 2011;53(1):11-18.

9. Leitersdorf E, Hobbs HH, Fouriet AM, Jacobst M, van der Westhuyzen DR, Coetzee GA. Deletion in the first cysteine-rich repeat of low density lipoprotein receptor impairs its transport. Proc Natl Acad Sci 1988;85(Nov):7912-7916.

10. Abera $A B$, Marais AD, Raal FJ, et al. Autosomal recessive hypercholesterolemia: Discrimination of ARH protein and LDLR function in the homozygous FH phenotype. Clin Chim Acta 2007;378(1):33-37. DOI:10.1016/.cca.2006.10.005

11. Marais AD, Solomon GAE, Blom DJ. Dysbetalipoproteinaemia: A mixed hyperlipidaemia of remnant lipoproteins due to mutations in apolipoprotein E. Crit Rev Clin Lab Sci 2014;51(1):46-62. DOI:10.3109/1 0408363.2013.870526

12. De Villiers WIS, van der Westhuyzen DR, Coetzee GA, Henderson HE, Marais AD. The apolipoprotein E2 (Arg145Cys) mutation causes autosomal dominant type iii hyperlipidemia with incomplete penetrance. Atheroscler Thromb Vasc Biol 1997;17(5):865-872.

Aheroscter

3. Bautovich GJ, Dash MJ, Hensley WJ, Turtle JR. Gradient gel electrophoresis of human plasma lipoproteins. Clin Chem 1973;19(4):415-418.

4. Blom DJ, Byrnes P, Jones S, Marais AD. Non denaturing polyacrolamide gradient gel electrophoresis for the diagnosis of dysbetalipoproteinemia. J Lipid Res 2003;44(1):212-217. DOI:10.1194/jlr.d200013-jl200

15. Ahaneku JE, Taylor GO, Agbedana EO, Walker O, Salako LA. Changes in lipid and lipoprotein values during a cross-over treatment of doxazosin, moduretic and amlodipine in hypertensive patients. J Pak Med Assoc 1994;44(7):166-169.

16. Grimm RH, Leon AS, Hunninghake DB, Lenz K, Hannan P, Blackburn H. Effects of thiazide diuretics on plasma lipids and lipoproteins in mildly hypertensive patients: A double-blind controlled trial. Ann Intern Med 1981;94(1):7-11.

17. Voora D, Shah SH, Reed CR, et al. Pharmacogenetic predictors of statin-mediated low-density lipoprotein cholesterol reduction and dose response. Circ Cardiovasc Genet 2008;1(2):100-106. DOI:10.1161/ CIRCGENETICS.108.795013

18. Manninen V, Tenkanen L, Koskinen P, et al. Joint effects of serum triglyceride and LDL cholesterol and HDL cholesterol concentrations on coronary heart disease risk in the Helsinki heart study. Circulation 1992;85(1):37-45

19. Virani SS. Non-HDL cholesterol as a metric of good quality of care. Tex Heart Inst J 2011;38(2):160-162

20. Blom DJ, O'Neill FH, Marais AD. Screening for dysbetalipoproteinemia by plasma cholesterol and apolipoprotein B concentrations. Clin Chem 2005;51(5):904-907. DOI:10.1373/clinchem.2004.047001

21. Blom DJ. A clinical approach to dyslipidaemia. Cont Med Educ 2009;27(3):108-114. 